\title{
Synthesis and reactivity of aliphatic sulfur pentafluorides from substituted (pentafluorosulfanyl)benzenes
}

\author{
Norbert Vida ${ }^{1, \S}$, Jiří Václavík ${ }^{1,2}$ and Petr Beier ${ }^{* 1}$
}

\author{
Full Research Paper \\ Address: \\ ${ }^{1}$ Institute of Organic Chemistry and Biochemistry, v.v.i., Academy of \\ Sciences of the Czech Republic, Flemingovo nám. 2, 16610 Prague \\ 6, Czech Republic and 2Laboratory of Molecular Structure \\ Characterization, Institute of Microbiology, v.v.i., Academy of \\ Sciences of the Czech Republic, Vídeňská 1083, 14220 Prague, \\ Czech Republic \\ Email: \\ Petr Beier - beier@uochb.cas.cz \\ * Corresponding author \\ $\S$ In memoriam. \\ Keywords: \\ dearomatization; decarboxylation; Diels-Alder reaction; oxidation; \\ pentafluorosulfanyl group
}

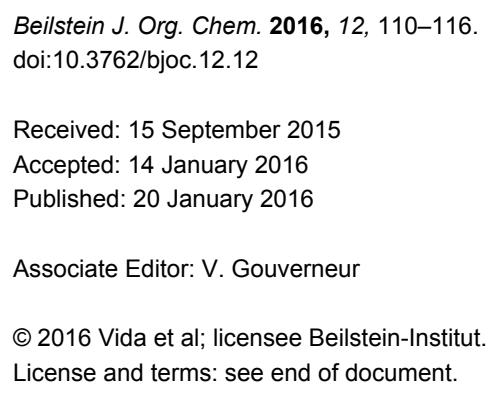

\begin{abstract}
Oxidation of 3- and 4-pentafluorosulfanyl-substituted anisoles and phenols with hydrogen peroxide and sulfuric acid provided a mixture of $\mathrm{SF}_{5}$-substituted muconolactone, maleic, and succinic acids. A plausible mechanism for the formation of the aliphatic $\mathrm{SF}_{5}$ compounds was presented and their chemical reactivity was investigated. $\mathrm{SF}_{5}$-substituted para-benzoquinone was synthesized; its oxidation led to an improved yield of 2-(pentafluorosulfanyl)maleic acid. The reaction of $\mathrm{SF}_{5}$-substituted maleic anhydride and para-benzoquinone with cyclopentadiene afforded the Diels-Alder adducts. Decomposition of 3-(pentafluorosulfanyl)muconolactone in acidic, neutral and basic aqueous media was investigated and the decarboxylation of 2-(pentafluorosulfanyl)maleic acid provided 3-(pentafluorosulfanyl)acrylic acid.
\end{abstract}

\section{Introduction}

Fluorinated organic compounds have been one of the foci of chemical industry for the last several decades. The unique properties of fluorine atoms and fluorinated groups have been exploited in various applications ranging from advanced materials to bioactive compounds [1-3]. One such fluorinated functional group which has become the focus of systematic investigation only recently is the pentafluorosulfanyl $\left(\mathrm{SF}_{5}\right)$ group
$[4,5]$. The combination of high stability [6], lipophilicity [7] and strong electron-withdrawing character [8] - similar to but more extreme than the trifluoromethyl group - makes $\mathrm{SF}_{5}$ compounds promising candidates for agrochemicals and pharmaceuticals [9]. Recent studies showed several cases where $\mathrm{SF}_{5}$ analogues of established compounds showed improved potency [10-12]. Limiting factors for a more widespread use of $\mathrm{SF}_{5}$ 
compounds are low accessibility of basic building blocks and the lack of understanding of their chemical behavior. Lack of availability of $\mathrm{SF}_{5}$ compounds is particularly evident in aliphatics where radical addition of expensive and toxic $\mathrm{SF}_{5} \mathrm{Cl}$ to unsaturated compounds is practically the only synthetic option currently available $[13,14]$. We have recently described an alternative route to access $\mathrm{SF}_{5}$ aliphatic compounds, based on oxidation of much more readily available aromatic ones [15]. One of the methods we developed was based on the oxidation of 4-(pentafluorosulfanyl)anisole (1) or 4-(pentafluorosulfanyl)phenol (2) by a mixture of aqueous hydrogen peroxide and concentrated sulfuric acid (Scheme 1). The major product was muconolactone $\mathbf{3}$ while maleic acid $\mathbf{4}$ and succinic acid 5 were formed in small amounts. Herein we report a full account of this oxidation, alternative syntheses of maleic acid $\mathbf{4}$, and the results of chemical reactivity studies of acids 3 and $\mathbf{4}$.

\section{Results and Discussion}

The proposed mechanism for the oxidation of 1 and $\mathbf{2}$ to $\mathrm{SF}_{5}$ containg products is shown in Scheme 2 [15]. The muconolactone derivative 3 is most probably the product of a series of transformations: electrophilic aromatic hydroxylation to the intermediate 6, oxidation to ortho-benzoquinone 7 , Baeyer-Villiger (BV) oxidation, hydrolysis to muconic acid derivative $\mathbf{8}$, and finally intramolecular conjugate addition affording 3. Under certain conditions, small amounts of intermediates $\mathbf{6}$ and $\mathbf{8}$ were detected [15]. Interestingly, this reaction sequence is essentially identical to the aerobic microbial degradation of aromatic compounds, which involves hydroxylating oxygenase and ring-cleaving dioxygenase enzymes [16-19]. This sequence of reactions however, does not account for the presence of maleic acid derivative $\mathbf{4}$ in the product mixture. Control experiments in which $\mathbf{8}$ or $\mathbf{3}$ were reacted with $\mathrm{H}_{2} \mathrm{O}_{2} /$

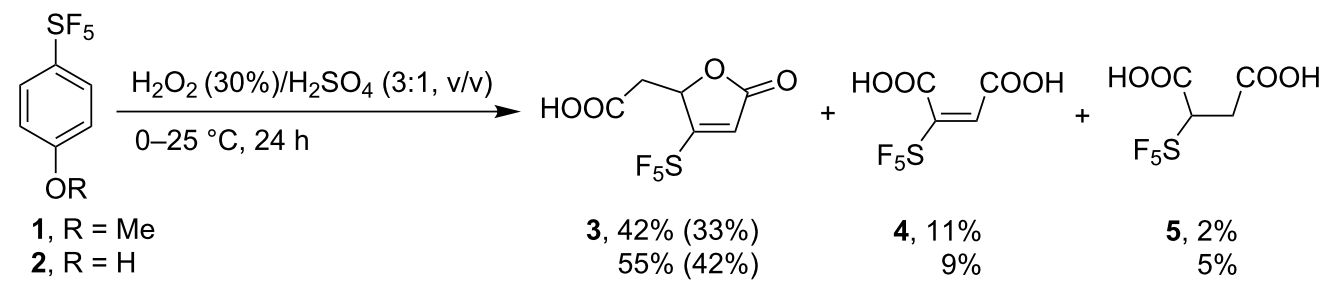

Scheme 1: Oxidation of $\mathrm{SF}_{5}$-anisole and phenol. ${ }^{19} \mathrm{~F}$ NMR yields are shown (isolated yields in parentheses).<smiles>[R]Oc1ccc(S(F)(F)(F)(F)F)cc1</smiles>

1, $\mathrm{R}=\mathrm{Me}$

2, $\mathrm{R}=\mathrm{H}$

$\mathrm{H}_{2} \mathrm{O}_{2} / \mathrm{H}_{2} \mathrm{SO}_{4}$

$\mathrm{S}_{\mathrm{E}} \mathrm{Ar}$

hydroxylation

$\underbrace{\text { oxidation }}_{O R}$

6, $\mathrm{R}=\mathrm{Me}$<smiles>O=C1C=CC(S(F)(F)F)=CC1=O</smiles>

7

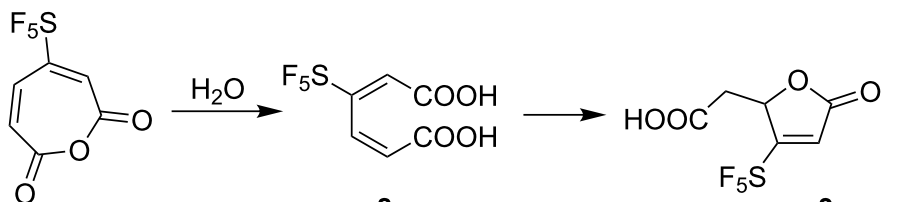

8

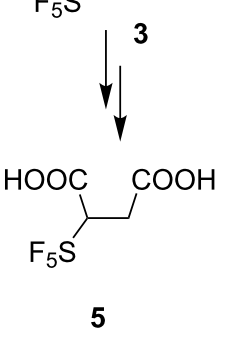

Scheme 2: Proposed mechanism for the formation of $\mathbf{3}$ and $\mathbf{4}$ from $\mathrm{SF}_{5}$ aromatics $\mathbf{1}$ and 2. 
$\mathrm{H}_{2} \mathrm{SO}_{4}$ did not provide 4 . This suggests that 4 may be formed by a second hydroxylation of $\mathbf{6}$ to 9 . The second electrophilic aromatic hydroxylation is a favorable process because $\mathbf{6}$ is a more activated substrate than $\mathbf{1}$ or $\mathbf{2}$. Oxidation, BV oxidation and hydrolysis would afford the diacid 4 (Scheme 2). Succinic acid derivative $\mathbf{5}$ is another minor product and a control experiment showed that it was formed from 3. Mechanistic considerations of this process will be discussed later.

We hypothesized that the yield of 4 might be increased when starting from 3-(pentafluorosulfanyl)anisole (10) or 3-(pentafluorosulfanyl)phenol (11). In these substrates, the first hydroxylation is likely to occur in the para position to the methoxy or hydroxy groups facilitating the formation of the para-benzoquinone derivative 12. To test this hypothesis, both 10 and 11 were subjected to oxidation by $\mathrm{H}_{2} \mathrm{O}_{2} / \mathrm{H}_{2} \mathrm{SO}_{4}$ mixture. Indeed, the yield of $\mathbf{3}$ decreased considerably while the yield of 4 increased somewhat but still remains low (Scheme 3).
The presumed intermediate 2-(pentafluorosulfanyl)-1,4-benzoquinone (12) in the pathway toward 4 was prepared independently (Scheme 4). Azo coupling [20] of phenol 11 with a diazonium salt prepared from sulfanilic acid afforded red azo product 13. The regioselectivity is governed by the strong paradirecting hydroxy group despite the presence of the bulky $\mathrm{SF}_{5}$ group. Compounds with substituents ortho to the $\mathrm{SF}_{5}$ group are relatively uncommon [21]. Reduction with sodium dithionite [20] provided aminophenol 14 in good overall yield and oxidation with $\mathrm{MnO}_{2}$ [22] gave benzoquinone 12 also in a good yield. Further oxidation with $\mathrm{H}_{2} \mathrm{O}_{2} / \mathrm{H}_{2} \mathrm{SO}_{4}$ resulted in a mixture of four $\mathrm{SF}_{5}$-containing products. Maleic acid 4 was identified in the mixture $\left(25 \%{ }^{19} \mathrm{~F}\right.$ NMR yield, Scheme 4$)$ but chromatographic separation, crystallization or derivatization $\left(\mathrm{CH}_{2} \mathrm{~N}_{2}\right)$ attempts were not successful. Nevertheless, these results show that $\mathrm{SF}_{5}$-substituted para-benzoquinones are most likely intermediates in the formation of $\mathbf{4}$ by oxidation of aromatics.

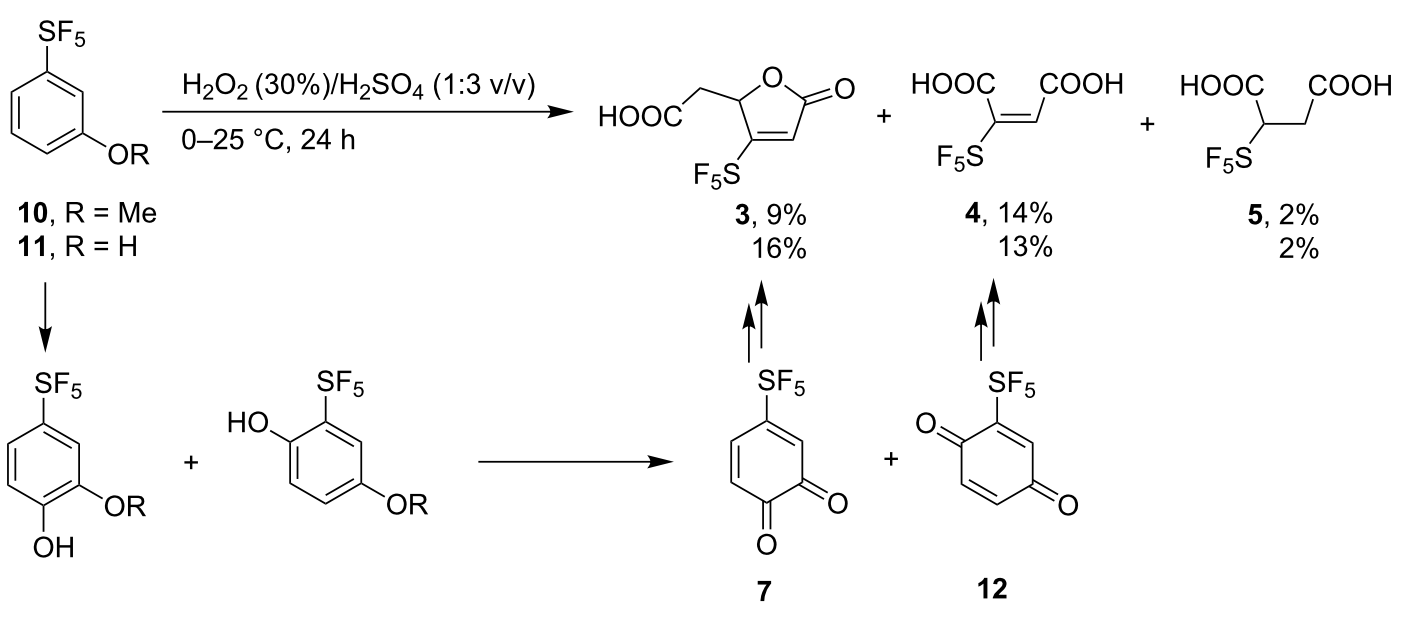

Scheme 3: Oxidation of anisole 10 and phenol $11 .{ }^{19} \mathrm{~F}$ NMR yields are given.
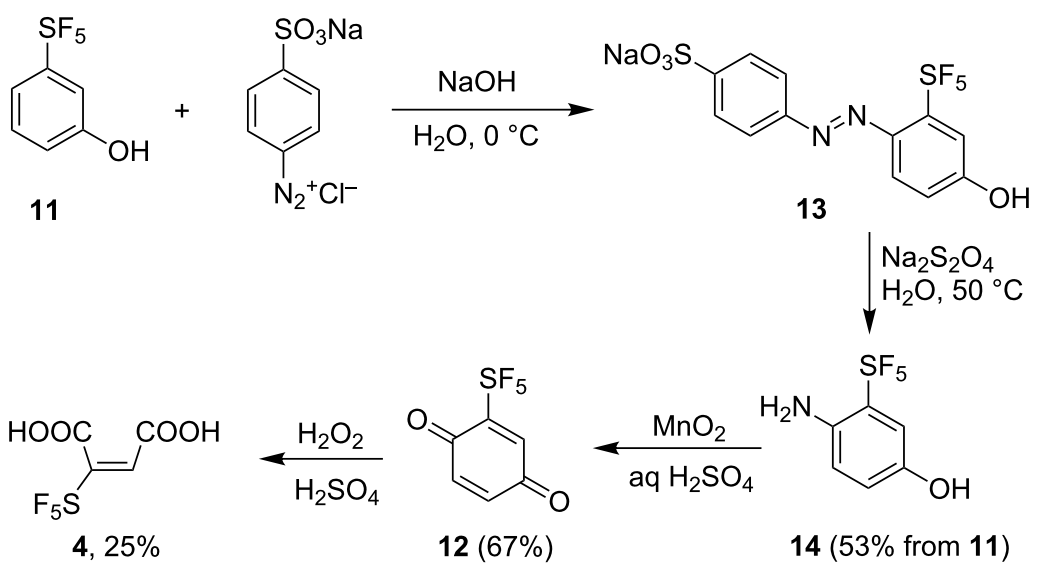
Benzoquinone $\mathbf{1 2}$ is a solid material with good stability at $-20{ }^{\circ} \mathrm{C}$. Several standard reactions were investigated. Reduction to hydroquinone $\mathbf{1 5}$ using catalytic palladium was very efficient (Scheme 5). The Diels-Alder reaction with cyclopentadiene proceeded in a high yield at ambient temperature with exclusive regiochemistry on the less substituted double bond of $\mathbf{1 2}$ and complete endo stereochemistry (Scheme 5).

Employing density functional theory (DFT) with the B3LYP functional [23] and the aug-cc-pVDZ basis set [24,25], we calculated the reaction coordinates leading to four possible Diels-Alder products (Table 1). Single-point energies of the transition states suggested that pathway a was preferred over $\mathbf{b}$ (difference of ca. 10-20 kJ/mol). This was further supported by comparison of Gibbs free energy values. Boltzmann distribution was used to calculate theoretical endo/exo selectivity of 16a (98:2) from the differences of Gibbs energy of the transition states.

Geometries of the four transition states are depicted in Figure 1. The less abundant transition states (TS-endo-16b and TS-exo16b) were asynchronous with the differences of bond lengths of 0.662 and $0.556 \AA$, respectively. Structures TS-endo-16a and TS-exo-16a also displayed a certain degree of asynchronicity with the bond length differences of 0.085 and $0.081 \AA$. The striking difference is probably caused by the steric demand of the $\mathrm{SF}_{5}$ group.

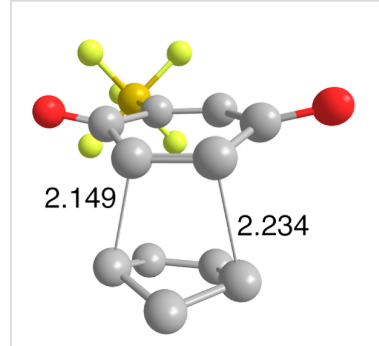

TS-endo-16a major

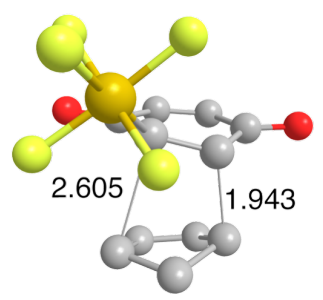

TS-endo-16b

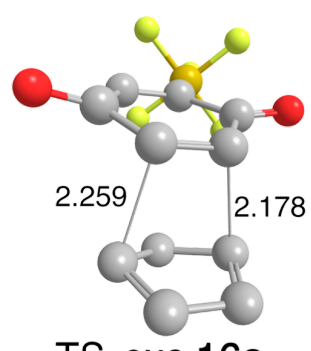

TS-exo-16a

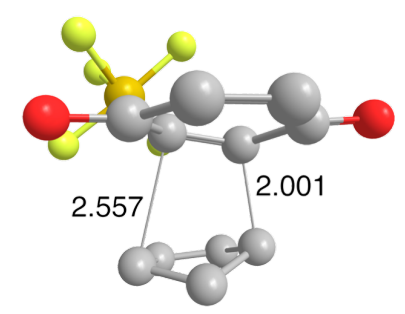

TS-exo-16b
Figure 1: Optimized geometries of transition states of Diels-Alder reaction of cyclopentadiene with 12 . Selected bond lengths are given in Ångström.

The chemical behavior of muconolactone $\mathbf{3}$ was investigated next. This compound showed good stability at ambient temperature in a strongly acidic and oxidizing environment. However,<smiles></smiles>

endo-16a $(92 \%)$

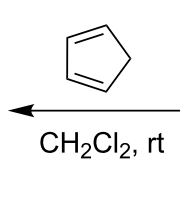

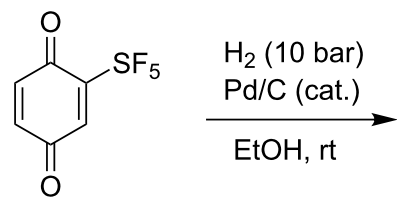

12<smiles>Oc1ccc(O)c(C(F)(F)F)c1</smiles>

$15(92 \%)$

Scheme 5: Catalytic hydrogenation and Diels-Alder reaction of benzoquinone 12.

Table 1: Calculated reaction coordinates of Diels-Alder reaction of 12 with cyclopentadiene. ${ }^{a}$

\begin{tabular}{|c|c|c|c|}
\hline energy (kJ/mol) & pathway & $E_{T s}{ }^{b}$ & $E_{\mathrm{P}}{ }^{c}$ \\
\hline single-point (Gibbs) & a-endo & $53.4(116.9)$ & $-57.4(15.9)$ \\
\hline & a-exo & $64.1(126.7)$ & $-55.7(20.1)$ \\
\hline & b-endo & $74.6(139.1)$ & $-61.2(14.8)$ \\
\hline & b-exo & $75.6(140.0)$ & $-58.1(20.2)$ \\
\hline
\end{tabular}

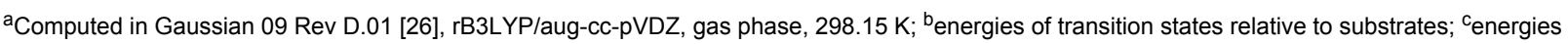
of products relative to substrates. 
lactone 3 was found to be unstable in water or in aqueous base. Monitoring a solution of 3 in $\mathrm{D}_{2} \mathrm{O}$ by ${ }^{1} \mathrm{H}$ and ${ }^{19} \mathrm{~F}$ NMR spectroscopy showed a gradual disappearance of the $\mathrm{SF}_{5}$ signal. After $55 \mathrm{~h}$ at ambient temperature two sets of signals appeared in the ${ }^{1} \mathrm{H}$ NMR spectrum; their integrals and coupling patterns suggested the presence of two structures of $\mathbf{1 7}$ in a 59:41 ratio. In DMSO- $d_{6}$ only the enol form of 17 was observed. Decomposition of $\mathbf{3}$ is much faster in the presence of sodium bicarbonate. In a preparative experiment, $\mathbf{3}$ was dissolved in water and after $40 \mathrm{~h}$ at ambient temperature acid $\mathbf{1 7}$ was isolated in $60 \%$ yield confirming that $\mathbf{3}$ undergoes addition of water and elimination of $\mathrm{HF}$ and $\mathrm{SF}_{4}$ (Scheme 6). Nucleophile-induced elimination of $\mathrm{SF}_{5}$ groups in $\beta$-position of an electron-withdrawing group has been described [27].

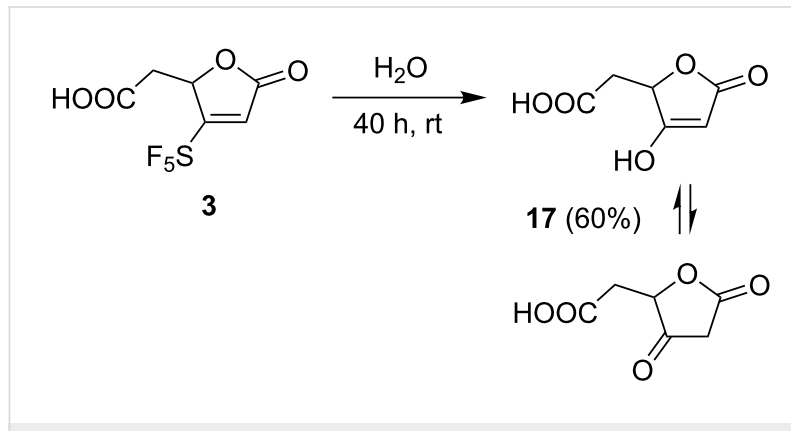

Scheme 6: Decomposition of 3 in water.

As already mentioned, compound $\mathbf{3}$ is much more stable in acidic than in neutral or basic aqueous medium. To investigate its reactivity in acids under various conditions, several screening experiments were carried out. In $\mathrm{HCl}(5 \mathrm{M}), \mathrm{H}_{2} \mathrm{SO}_{4}$ ( $5 \mathrm{M}$ or $10 \mathrm{M}$ ) or $85 \% \mathrm{H}_{3} \mathrm{PO}_{4}$ at ambient temperature the lactone 3 remained unaffected. At $80{ }^{\circ} \mathrm{C}$ the formation of levulinic acid derivative $\mathbf{1 8}$ was observed together with unidentified byproducts. Under elevated temperature $\left(100{ }^{\circ} \mathrm{C}\right.$ and above) the product of $\mathrm{HF}$ and $\mathrm{SF}_{4}$ elimination, (E)-4-oxopent-2enoic acid (19) [28] formed (Scheme 7). In a preparative experiment using $85 \% \mathrm{H}_{3} \mathrm{PO}_{4}$ at $100{ }^{\circ} \mathrm{C}$, levulinic acid 18 was obtained in $14 \%$ yield. This result allowed us to propose that byproduct 5 observed during oxidation of $\mathrm{SF}_{5}$-anisoles and phenols could be formed from open-chain acids according to Scheme 7.

Despite the lack of efficient synthetic protocols toward maleic acid 4, some basic chemical reactivity studies were performed. When heated to about $125^{\circ} \mathrm{C}$ under reduced pressure, acid 4 eliminated water to afford anhydride 20 in a good yield. Anhydride 20 underwent a Diels-Alder reaction with cyclopentadiene at ambient temperature to provide a mixture of endo and exo products in an 8:1 ratio (Scheme 8). In comparison, it is

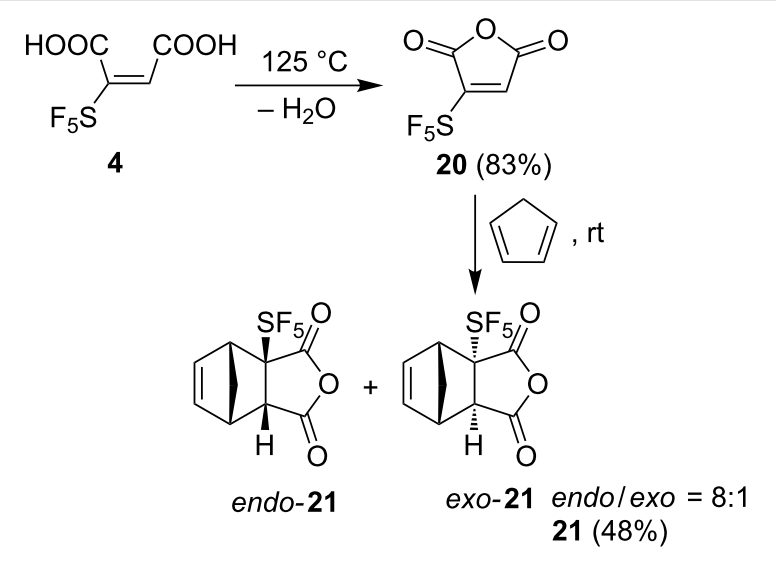

Scheme 8: Synthesis of maleic anhydride $\mathbf{2 0}$ and Diels-Alder adducts 21.

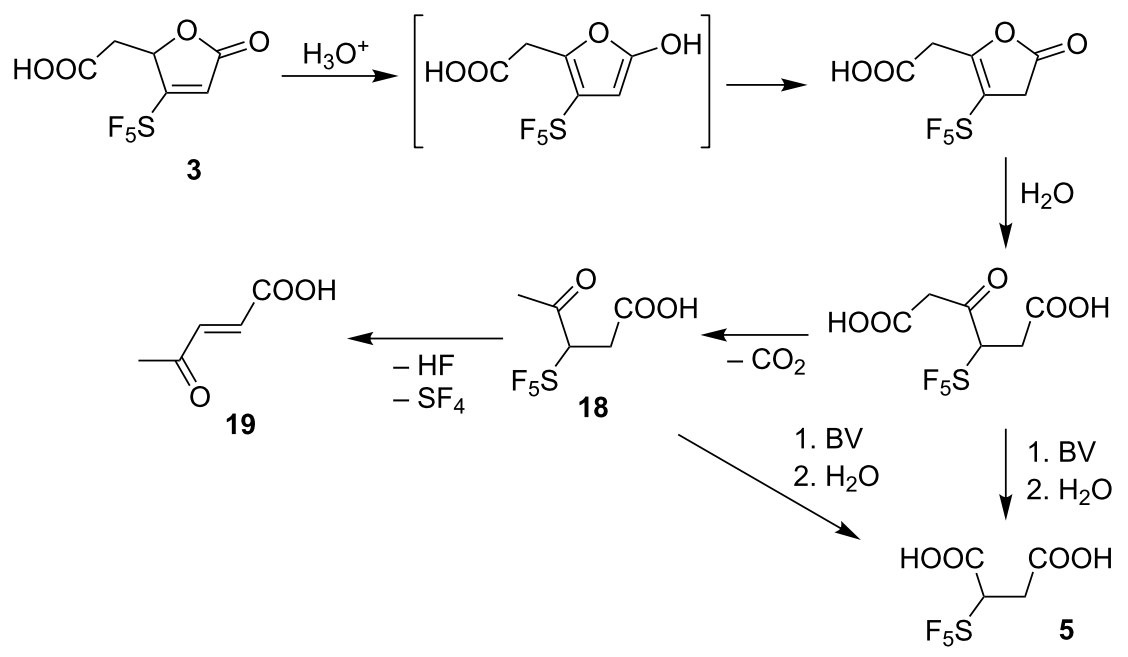


known that maleic anhydride in analogous reactions affords exclusively the endo adduct [29].

Attempts to facilitate the isolation of very polar maleic acid 4 from the reaction mixture by derivatization to dimethyl ester using diazomethane were not successful. The dimethyl maleate derivative was formed but was accompanied by the $[3+2]$ cycloaddition product 22 . With excess of diazomethane, clean and efficient formation of $\mathbf{2 2}$ was observed (Scheme 9).

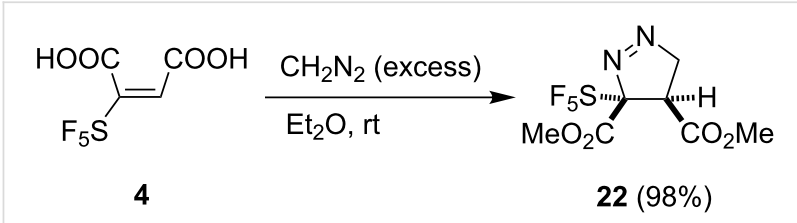

Scheme 9: Reaction of maleic acid 4 with diazomethane.

Acid 4 was stable in water, methanol, isopropylalcohol, boiling benzene, or boiling aqueous sodium carbonate. However, it underwent decarboxylation in DMSO- $d_{6}$. Monitoring by NMR showed decarboxylation even at room temperature. After $90 \mathrm{~h}$ at ambient temperature the starting compound $\mathbf{4}$ disappeared and 3-(pentafluorosulfanyl)prop-2-enoic acid (23) was formed. At $65{ }^{\circ} \mathrm{C}$ the starting material was no longer present after $1.5 \mathrm{~h}$ and the NMR yield of the acrylic acid derivative $\mathbf{2 3}$ was $60 \%$ (Scheme 10). Acrylic acid $\mathbf{2 3}$ was prepared previously by the addition of $\mathrm{SF}_{5} \mathrm{Cl}$ to allyl alcohol and subsequent elimination and oxidation [30]. We proposed that the decarboxylation reaction could be used for the synthesis of selectively deuterium labelled acrylic acid derivative 23. Indeed, when maleic acid 4 was evaporated twice with $\mathrm{D}_{2} \mathrm{O}$ to exchange acidic protons and heated in DMSO- $d_{6}$, deuterated $\mathbf{2 3}$ was observed by NMR spectroscopy (Scheme 10).

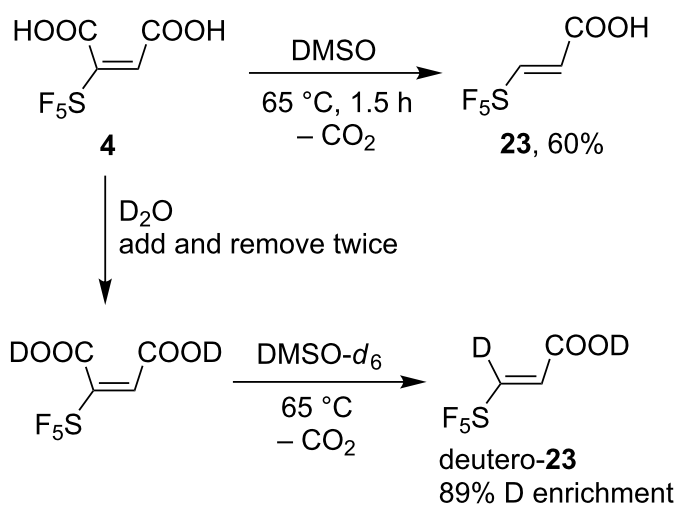

Scheme 10: Decarboxylation of maleic acid 4 to acrylic acid 23 in DMSO and the preparation of deuterium labelled 23.

\section{Conclusion}

In conclusion, similar to 4-(pentafluorosulfanyl)anisole and 4-(pentafluorosulfanyl)phenol the meta-derivatives $\mathbf{1 0}$ and $\mathbf{1 1}$ underwent oxidation with aqueous hydrogen peroxide in sulfuric acid to provide $\mathrm{SF}_{5}$-muconolactone and $\mathrm{SF}_{5}$-maleic acid as main products. Improved conversion of $\mathrm{SF}_{5}$-maleic acid was rationalized by preferential formation of $\mathrm{SF}_{5}$-substituted para-benzoquinone as an intermediate. This benzoquinone was independently prepared and its transformation to the maleic acid derivative by oxidation was verified. Reactions of $\mathrm{SF}_{5}$ maleinanhydride (formed by dehydration of $\mathrm{SF}_{5}$-maleic acid) and $\mathrm{SF}_{5}$-benzoquinone with cyclopentadiene provided the Diels-Alder adducts in good to excellent yields; the observed stereoselectivity of the latter reaction agreed with DFT calculations. $\mathrm{SF}_{5}$-muconolactone was found to be relatively stable in acidic media but eliminates the $\mathrm{SF}_{5}$ group in water or in aqueous base to form 2-(3,5-dioxotetrahydrofuran-2-yl)acetic acid, which in aqueous solution exists in equilibrium with its enol form. Further experiments are underway to find out whether aerobic microbial degradation of $\mathrm{SF}_{5}$-substituted aromatic compounds follows the same pathway as our chemical oxidation method.

\section{Supporting Information}

Synthesis and characterization of all new products, copies of ${ }^{1} \mathrm{H},{ }^{13} \mathrm{C}$, and ${ }^{19} \mathrm{~F}$ NMR spectra of newly synthesized products, and computational data.

\section{Supporting Information File 1}

Experimental part.

[http://www.beilstein-journals.org/bjoc/content/ supplementary/1860-5397-12-12-S1.pdf]

\section{Acknowledgements}

This work was supported by the Academy of Sciences of the Czech Republic (Research Plan RVO: 61388963).

\section{References}

1. Kirsch, P. Modern Fluoroorganic Chemistry; Wiley-VCH: Weinheim, Germany, 2013. doi:10.1002/9783527651351

2. Swallow, S. Fluorine-Containing Pharmaceuticals. In Fluorine in Pharmaceutical and Medicinal Chemistry; Gouverneur, V.; Müller, K., Eds.; Molecular Medicine and Medicinal Chemistry, Vol. 6; Imperial College Press: London, 2012; pp 141-174. doi:10.1142/9781848166363_0005

3. Purser, S.; Moore, P. R.; Swallow, S.; Gouverneur, V. Chem. Soc. Rev. 2008, 37, 320-330. doi:10.1039/b610213c

4. Altomonte, S.; Zanda, M. J. Fluorine Chem. 2012, 143, 57-93. doi:10.1016/j.jfluchem.2012.06.030 
5. Savoie, P. R.; Welch, J. T. Chem. Rev. 2015, 115, 1130-1190. doi:10.1021/cr500336u

6. Sheppard, W. A. J. Am. Chem. Soc. 1962, 84, 3064-3072. doi:10.1021/ja00875a006

7. Hansch, C.; Leo, A.; Unger, S. H.; Kim, K. H.; Nikaitani, D.; Lien, E. J. J. Med. Chem. 1973, 16, 1207-1216. doi:10.1021/jm00269a003

8. Sheppard, W. A. J. Am. Chem. Soc. 1962, 84, 3072-3076. doi:10.1021/ja00875a007

9. Crowley, P. J.; Mitchell, G.; Salmon, R.; Worthington, P. A. Chimia 2004, 58, 138-142. doi:10.2533/000942904777678172

10. Lim, D. S.; Choi, J. S.; Pak, C. S.; Welch, J. T. J. Pestic. Sci. (Tokyo, Jpn.) 2007, 32, 255-259. doi:10.1584/jpestics.G06-50

11. Welch, J. T.; Lim, D. S. Bioorg. Med. Chem. 2007, 15, 6659-6666. doi:10.1016/j.bmc.2007.08.012

12. Wipf, P.; Mo, T.; Geib, S. J.; Caridha, D.; Dow, G. S.; Gerena, L.; Roncal, N.; Milner, E. E. Org. Biomol. Chem. 2009, 7, 4163-4165. doi:10.1039/b911483a

13. Case, J. R.; Ray, N. H.; Roberts, H. L. J. Chem. Soc. 1961, 2066-2070. doi:10.1039/JR9610002066

14. Aït-Mohand, S.; Dolbier, W. R., Jr. Org. Lett. 2002, 4, 3013-3015. doi:10.1021/ol026483o

15. Vida, N.; Pastýř́íková, T.; Klepetářová, B.; Beier, P. J. Org. Chem. 2014, 79, 8906-8911. doi:10.1021/jo501562z

16. Que, L., Jr.; Ho, R. Y. N. Chem. Rev. 1996, 96, 2607-2624. doi:10.1021/cr960039f

17. Ullrich, R.; Hofrichter, M. Cell. Mol. Life Sci. 2007, 64, 271-293. doi:10.1007/s00018-007-6362-1

18. Fuchs, G.; Boll, M.; Heider, J. Nat. Rev. Microbiol. 2011, 9, 803-816. doi:10.1038/nrmicro2652

19. Diaz, E.; Jiménez, J. I.; Nogales, J. Curr. Opin. Biotechnol. 2013, 24 , 431-442. doi:10.1016/j.copbio.2012.10.010

20. Dieks, H.; Senge, M. O.; Kirste, B.; Kurreck, H. J. Org. Chem. 1997, 62, 8666-8680. doi:10.1021/jo970752k

21. Sipyagin, A. M.; Bateman, C. P.; Tan, Y.-T.; Thrasher, J. S. J. Fluorine Chem. 2001, 112, 287-295. doi:10.1016/s0022-1139(01)00514-0

22. Boros, E. E.; Kaldor, I.; Turnbull, P. S. J. Heterocycl. Chem. 2011, 48, 733-736. doi:10.1002/jhet.571

23. Becke, A. D. J. Chem. Phys. 1993, 98, 5648-5652. doi:10.1063/1.464913

24. Dunning, T. H., Jr. J. Chem. Phys. 1989, 90, 1007-1023. doi:10.1063/1.456153

25. Kendall, R. A.; Dunning, T. H., Jr.; Harrison, R. J. J. Chem. Phys. 1992, 96, 6796-6806. doi:10.1063/1.462569

26. Gaussian 09, Revision D.01; Gaussian, Inc.: Wallingford, CT, USA, 2013.

27. Dolbier, W. R., Jr.; Zheng, Z. J. Org. Chem. 2009, 74, 5626-5628. doi:10.1021/jo9007699

28. Seltzer, S.; Stevens, K. D. J. Org. Chem. 1968, 33, 2708-2711. doi:10.1021/jo01271a020

29. Zhang, Z.; Peng, Z.-W.; Hao, M.-F.; Gao, J.-G. Synlett 2010, 2895-2898. doi:10.1055/s-0030-1259030

30. Brel, V. K. Synthesis 2006, 339-343. doi:10.1055/s-2005-918508

\section{License and Terms}

This is an Open Access article under the terms of the Creative Commons Attribution License

(http://creativecommons.org/licenses/by/2.0), which permits unrestricted use, distribution, and reproduction in any medium, provided the original work is properly cited.

The license is subject to the Beilstein Journal of Organic Chemistry terms and conditions:

(http://www.beilstein-journals.org/bjoc)

The definitive version of this article is the electronic one which can be found at:

doi:10.3762/bjoc. 12.12 